\title{
Exporting Finnish Agricultural Advisory Knowhow - Training of Agricultural Advisors in Kosovo
}

\author{
Kati Partanen ${ }^{1}$, Ardita Jahja-Hoxha ${ }^{1,2}$, Jussi Juhola ${ }^{3}$, Paavo Maskulainen ${ }^{1}$ \\ 1) Savonia University of Applied Sciences, P.O.box 72, 74101 Iisalmi, Finland, \\ forename.surname@savonia.fi \\ 2) University of Prishtina, Agriculture and Veterinary Faculty, Boulevard "Bill Clinton", no nr. \\ 10000 Prishtina, Kosovo, ardita.hoxha@uni-pr.edu \\ 3) Association of ProAgriaCentres, P.O Box 251,01301Vantaa, jussi.juhola@proagria.fi
}

\begin{abstract}
In Kosovo conditions for agricultural production are good, climate in the region is close to ideal. However, local agricultural production is relatively low and income from agriculture for the rural population is extremely low. One of the key challenges in developing the agricultural sector and employment within is the knowledge base. Lack of business skills and modern agricultural methods added with practically no access to advisory services is the key barrier for further development of the sector. The aim of this project was to develop Kosovan agriculture through building the capacity of agricultural advisory by constructing a modern curriculum model and developing the advisors' ability to help farms to develop their entrepreneurship.

The steps of the projects were: 1 . Building a modern curriculum of agricultural advisory training according to the local needs. 2. Emphasizing the expertize of the advisor students by team working method. 3. Testing the knowledge: real enterprise's development process and result analysis. 4. Evaluating the project and methods used.

The curriculum was built according to the competences defined in four workshops organized for stakeholders in Kosovo. Five competence areas were recognized: Communication skills, Business competence, Development competence, Production competence and Key skills for lifelong learning. Students participating in the training (27) were required to have at least a Bachelor's degree in agriculture or related fields. The training itself was organized by team training method. The training consisted of lectures, team and independent studying and working as a team with a real farm enterprise advisory case. The team learning process was guided to increase the students' knowledge of team building in working life. Five student teams identified the main development needs in a real enterprise case and planned a way to realize them. The entrepreneurs were satisfied with the concrete development realized during the project.

Both students and stakeholders evaluated the project to be very successful. The students' satisfaction was evaluated by a web questionnaire and the stakeholders' satisfaction through six focus group discussions organized in different parts of the country. $90 \%$ of the students found training beneficial for their future career and all students were satisfied with the training. This new training model requires good cooperation among stakeholders but increases capacities of all counterparts. The Finnish agricultural advisory and training knowledge has demand.
\end{abstract}

Keywords: Kosovo, agricultural advisory services, agricultural extension, continuing education 


\section{Introduction}

Local agricultural production in Kosovo is currently relatively low, despite of estimates that the growing conditions and climate in the region are close to ideal. Agricultural products readily available in retail stores and markets are largely imported whereas local products get very little shelf space. Similarly, production inputs such as animal feed and fertilizers are largely imported. The result of this is that income from agriculture for the rural population is extremely low, consequently resulting in producers' inability to acquire production inputs. This keeps production levels very low.

Kosovo's economy is very much dependent on agricultural and rural activities. Before the conflicts in 1998 - 1999, about $60 \%$ of the employment was created by rural activities, including agriculture, forestry and agro-business. Agriculture is still the most important branch of the Kosovo economy. According to official statistics, agriculture, forestry and fishing employs $4,6 \%$ of the population, manufacturing employs $14,3 \%$, trade $13,4 \%$, education $12,0 \%$ and construction 9,5\% (Kosovo Agency for Statistics 2013). However in other sources the share of agriculture in labor is bigger as most of the agricultural labor is not official and majority of the agriculture is still subsistence. Ministry of Agriculture, Forestry and Rural Development (2009) estimates that agriculture, forestry and fishing employs $15 \%$ of the Kosovan population.

Despite the positive prospects for development, agriculture generally remains a rather inefficient sector and local entrepreneurs are still unable to capitalize upon the potential presented therein. In particular, the entrepreneurial orientation of Kosovo's agribusinesses is not achieving its full potential despite progress made through joint efforts of entrepreneurs, international donors and local institutions. The reason for this situation is lack of coordination of activities and the non-existence of an efficient advising system.

Because of its special political and socio-economic conditions, in the post-war period, Kosovo has been subjected to extreme business environment conditions affecting entrepreneurship development during various stages. Kosovo has experienced delayed transition characterized by the process of privatization, structural reforms and adaptation of a market oriented economic system. The relatively new locally owned companies face the new challenge of increasing their competitiveness in domestic market, as well as in the regional markets. The competitiveness in the domestic market is the potential for substituting imports in the agriculture sector, where local processing capacities have rapidly grown in the past two years. For most of the processors, the growth of processing capacities was also a result of direct support from donor programs or subsidy schemes, hence, testifying to the need and effectiveness of such support. In addition to that, numerous donor programs have also supported entrepreneurship and start-up support schemes, which often had dairy as the priority sector.

During the first phase of reconstruction of Kosovo, numerous donor organizations have focused their efforts in revitalizing the agriculture sector. The donor support, which is still active, has mainly been administrated in the form of grants (milk cows, machinery, greenhouses, small scale infrastructure support, etc.). Currently, the country's agricultural sector is evolving into a more mature stage of development, where the focus shifts into establishing more favorable policies for agriculture, transfer of new technologies of farming and reorienting farmers from subsistence to commercial and market oriented production.

The majority of agricultural land is privately owned, providing subsistence farming for individual households. Although Kosovo's agriculture sector is generally characterized by small farms, low productivity, and the absence of advisory services, agriculture contributes around $14 \%$ of Kosovo's GDP (Kosovo Agency of Statistics, 2012).

\section{Material and Methods}

The agricultural situation called for a strong advisory service to counteract the industrial forces at play in the agricultural scene. Local production should be increased in volume and improve its quality to achieve gradual shift in the local market towards locally produced goods and locally produced production inputs. Improving markets for local agricultural products improves rural areas' employment and welfare. 
Examples of such a shift already exist amongst various small-scale projects aimed at developing specific production areas, such as sweet peppers or strawberries. This project aimed to capitalize on the results achieved from the earlier projects as well as lay down the groundwork for development of an efficient agricultural advisory service.

One of the key challenges in developing the agricultural sector and employment within is the knowledge base. Lack of business skills and modern agricultural methods added with practically no access to advisory services is the key barrier for further development of the sector.

The project partners were Savonia University of Applied Sciences, Association of ProAgria Centres and University of Prishtina. Savonia UAS offers agricultural education at Bachelor and Master levels and has a leading role in agricultural development projects in North Savo region. ProAgria Centres offer agricultural advisory services in all fields of agriculture in Finland and has experience in exporting agricultural advisory knowledge. University of Prishtina's Faculty of Agriculture and Veterinary educates at both Bachelor and Master levels and has a stable position in Kosovo and is constantly developing its functions.

In the short run the development of functioning agricultural advisory services is indispensable. The first step towards this was establishing the advisory training within local higher education, to the Faculty of Agricultural and Veterinary Sciences in University of Prishtina. Most of the students in the faculty are not carrying their studies beyond the Bachelor level and the employment opportunities for the graduates in Kosovo have been scarce. This is partly due to the current challenging employment market in Kosovo, but also due to lack of working experience and vocational orientation of graduates not attained during the studies. The graduates have the basic agricultural and research skills yet they still need the business development, communication and networking skills in order to be able to work as efficient agricultural advisors.

In the long run the basic vocational education of farmers is also a vital question, but development of advisory skills and concept would have more rapid effects on economical and hitherto on employment of the agricultural sector. It is also a more cost efficient way of building capacities of local agriculture.

These development needs have also been recognized and set as a priority in the latest Agriculture and Rural Development Plan (2009 - 13) of Kosovan Ministry of Agriculture, Forestry and Rural Development (2009). "Developing skilled and experienced Rural Advisory Service" is presented as one key action for addressing weaknesses in human resource and management field (p. 29). Improving human potential by advisory service development is also consisting part of a specific objective of EU's development plan for the ministry. The project's approach and objectives were well in line with the ones of Kosovan Ministry of Agriculture, Forestry and Rural Development.

The project was named as "Training Agricultural Advisors in Kosovo (TAGAK)" and was financed by the Ministry for Foreign Affairs of Finland. Its objective was firstly to build the capacity of an existing group of agricultural professionals, and therefore to ensure direct employment of the trainees. Similarly, agricultural advisory services commonly contribute to the overall development of the agricultural sector and the abilities of persons involved in agriculture. The project also indirectly supported the development of employment in the agricultural sector in itself and promoted entrepreneurship within the industry. Furthermore, the proposed training module involved on-the-job training in order to ensure a practical approach as well as the development of easily applicable skills for the advisors in terms of supporting local farmers.

The approach taken in the project consisted of three stages: fact finding and needs assessment, developing of curricula, and training a pilot. The fact finding and needs assessment stage was primarily done by means of identifying and interviewing stakeholders as well as donor organizations working on the agricultural sector in Kosovo at the time. As is the case in many developing countries development aid efforts in Kosovo, although extensive, experience some lack of coordination amongst donors (Kotilainen, 2013). Aid tends to be somewhat localized addressing the needs of specific areas or target groups rather than addressing the agricultural support system as a whole. This issue is very common within development aid across all sectors, as shown by a study done on the health care development aid of USA, 
where it is concluded that development aid tends to target specific diseases rather than the health care basics and infrastructure. (Garret, Laurie. 2007)

In order to address this issue, extensive interviews of development aid project representatives from various countries were done as a part of the fact finding stage. The rest of the stakeholder interviews were held in the form of participatory workshops for specific target groups; the first one for farmers and farmer organizations, second one for ministry and municipalities' staff as well as public and private advisory personnel and the third one for the agricultural finance sector in Kosovo. The main challenges identified in all three workshops were surprisingly uniform in nature; the foremost being the lack of knowledge in agricultural produce marketing and communication skills. Based on the stakeholder's opinions and the workshop results five competences were defined to be focused on during the training: 1. Communication skills, 2. Business Competence (including business and investment planning, basic financial concepts and record keeping), 3. Development Competence (including challenge detecting, project development, planning and management), 4. Production Competence (based on trainees' previous specialization) and 5. Lifelong Learning Skills.

Competence based curricula was planned together with the project partners. The studies were planned to be carried out during two university semesters and be possible also for employed people to attend. Therefore it consisted of multiple learning activities including contact days as well as individual and team tasks. The extent of studies was 30 ECTS credits, which corresponds to 800 hours of student work. To apply to the training one had to have at least a Bachelor level education from agriculture or related field (e.g. veterinary, economics).

Savonia UAS has good experiences in using team pedagogics in adult trainings. In the training model used in TAGAK project the trainee group, which consisted of 30 trainees, was divided into five teams. Each member in the team represented different backgrounds of specialization (e.g. animal husbandry, plant production, agricultural economics, veterinary). Another pedagogical approach was case learning. Each team received a real case farm where they were training the advisory work. It is a motivating way to work as trainees can implement the lessons learned into practice and receive feedback. Case farms represented various fields of Kosovan agriculture: dairy farm, sheep farm, fruit farm, wine farm with winery and vegetable collection point. Each trainee team was guided by a tutor teacher from the University of Prishtina. The studies were realized in three study modules which described the advisory tasks in the case farm and courses to support the tasks. The first module was "Identifying the challenges", the second "Testing the practices" and the third "Analyzing and adjusting".

The actual training was mainly the responsibility of the teacher team of University of Prishtina's Faculty of Agriculture and Veterinary. The team was trained to the methods used in an intensive week held in Finland before the training. They also received mentoring from the Finnish project partners throughout the training. Finnish experts prepared e-lectures and also visited the actual training in Kosovo four times during the eight-month-training period.

\section{Results}

The trainees were evaluated by the teacher team based on the reports from their team's advisory case for a real farm. In addition, self-assessment as well as peer assessment was required. 27 trainees participated actively in the whole training and finalized all given tasks. The case farms were very satisfied with the trainee teams' work. All farms benefitted from the advises given and developed based on the advise and development plans given by the trainee teams.

The training was evaluated by a questionnaire to the trainees as well as with focus group discussions held in five municipalities in Kosovo. The trainees answered to the questionnaire anonymously in the internet after the training was finished. The questions handled the trainees' satisfaction with the training methods used. Also other feedback was asked.

Right after the training $59 \%$ of the trainees were employed $(n=27)$. Some of the trainees were still studying at Master level at University of Prishtina after the TAGAK training and were not employed. The 
trainees were satisfied with the team training method and case studies and overall organization of the training. $90 \%(\mathrm{n}=19)$ found the training useful when applying for a job.

Six focus group discussions were organized to farmers in six municipalities in Kosovo. All together 40 people attended the discussions arranged. All participants were aware of the TAGAK project and were satisfied with the logic behind it. They wished for more capacity building for the advisory services in Kosovo. The results of the discussions showed that the curricula and the diversity that TAGAK project provided was beneficial for the whole agricultural industry. Stakeholders' interest was in gaining as much advises ideas and suggestions as they could get from TAGAK advisers (trainees), in order to improve their farm production. The stakeholders' interest was focused on the opportunity that similar projects should give to experts from 'older' generations, meaning that the older agriculture experts can exchange the information with the young experts, where the credibility of advisory services would be much bigger and in the same time productive. In order to achieve more positive results in giving the service of the agriculture adviser the stakeholders' agreed that the services should be given as a team or group of advisers. TAGAK project has had an impact in improving the advisory services, and some of the skills learned during the TAGAK training are passed on to the advisers as well as to their clients.

Minister of Agriculture, Forestry and Rural Development of Kosovo, Blerand Stavileci (2013) has expressed his satisfaction with the TAGAK project method and results and the cooperation between the Ministry and the project.

\section{Conclusion}

Training such as TAGAK requires good cooperation between project partners and also with stakeholders. Development projects should be in line with the target country's development strategy and therefore connections with the local ministry are recommended. If a training project consists of new training methods it is important to train the trainers well and also build a mentoring system between the project partners. Mentoring can be realized through e-tools, like email and web conference tools, but also face-toface meetings are needed during the actual training. The curricula planning together with all project partners and based on needs commits them to the project. It also ensures that the training's content is meeting local needs. Working in close cooperation with project partners and stakeholders increases capacities of all counterparts in the project. Finnish agricultural advisory and education knowledge can be exported.

\section{References}

Garret, Laurie. 2007. The Challenge of Global Health. Foreign Affairs 88: 14 - 38 .

Kotilainen, Vesa. 2012-03-08. First secretary. [Interview.] Prishtina, Kosovo: Embassy of Finland. Kosovo Agency for Statistics. 2013. Results of the Kosovo 2012 labour force survey. [Accessed December 09 2013.] Available: http://esk.rksgov.net/ENG/dmdocuments/RESULTS\%20OF\%20THE\%20KOSOVO\%202012\%20LABOUR\%20FOR CE\%20SURVEY.pdf

Kosovo Agency of Statistics. 2012. Gross Domestic Product by Activities (2006 - 2011). Series 3: Economic Statistics.

Ministry of Agriculture, Forestry and Rural Development. 2009. Agriculture and Rural Development Plan 2009 - 13. Pristina, Republic of Kosovo. [Accessed December 09 2013.] Available: http://www.mbpzhr-ks.net/documents/743026_Agriculture_and_Rural_Development_Plan_2009-13.pdf Stavileci, Blerand. 2013-09-19. Minister of Agriculture, Forestry and Rural Development. [Interview.] Prishtina, Kosovo: Ministry of Agriculture, Forestry and Rural Development. 